\title{
Barriers and facilitators to implementing shared decision-making in clinical practice: a systematic review of health professionals' perceptions

\author{
Karine Gravel ${ }^{1}$, France Légaré* ${ }^{*}, 2$ and Ian D Graham ${ }^{3}$
}

Address: ${ }^{1}$ Research Centre of the Centre Hospitalier Universitaire de Québec, Québec, Canada, ${ }^{2}$ Department of Family Medicine, Université Laval, Québec, Canada and ${ }^{3}$ Faculty of Health Sciences, University of Ottawa, Ottawa, Canada

Email: Karine Gravel - karine.gravel@crsfa.ulaval.ca; France Légaré* - france.legare@mfa.ulaval.ca; Ian D Graham - igraham@ohri.ca

* Corresponding author

Published: 9 August 2006

Implementation Science 2006, I:16 doi:10.1 186/1748-5908-1-16
Received: 3 May 2006

Accepted: 9 August 2006

This article is available from: http://www.implementationscience.com/content///1/16

(C) 2006 Gravel et al; licensee BioMed Central Ltd.

This is an Open Access article distributed under the terms of the Creative Commons Attribution License (http://creativecommons.org/licenses/by/2.0), which permits unrestricted use, distribution, and reproduction in any medium, provided the original work is properly cited.

\begin{abstract}
Background: Shared decision-making is advocated because of its potential to improve the quality of the decision-making process for patients and ultimately, patient outcomes. However, current evidence suggests that shared decision-making has not yet been widely adopted by health professionals. Therefore, a systematic review was performed on the barriers and facilitators to implementing shared decisionmaking in clinical practice as perceived by health professionals.

Methods: Covering the period from 1990 to March 2006, PubMed, Embase, CINHAL, PsycINFO, and Dissertation Abstracts were searched for studies in English or French. The references from included studies also were consulted. Studies were included if they reported on health professionals' perceived barriers and facilitators to implementing shared decision-making in their practices. Shared decision-making was defined as a joint process of decision making between health professionals and patients, or as decision support interventions including decision aids, or as the active participation of patients in decision making. No study design was excluded. Quality of the studies included was assessed independently by two of the authors. Using a pre-established taxonomy of barriers and facilitators to implementing clinical practice guidelines in practice, content analysis was performed.

Results: Thirty-one publications covering 28 unique studies were included. Eleven studies were from the UK, eight from the USA, four from Canada, two from the Netherlands, and one from each of the following countries: France, Mexico, and Australia. Most of the studies used qualitative methods exclusively (I8/28). Overall, the vast majority of participants $(n=2784)$ were physicians $(89 \%)$. The three most often reported barriers were: time constraints (18/28), lack of applicability due to patient characteristics (I2/28), and lack of applicability due to the clinical situation (12/28). The three most often reported facilitators were: provider motivation (I5/28), positive impact on the clinical process $(\mathrm{I} / / 28)$, and positive impact on patient outcomes (10/28).

Conclusion: This systematic review reveals that interventions to foster implementation of shared decision-making in clinical practice will need to address a broad range of factors. It also reveals that on this subject there is very little known about any health professionals others than physicians. Future studies about implementation of shared decision-making should target a more diverse group of health professionals.
\end{abstract}




\section{Background}

Shared decision-making (SDM) is defined as a decision making process jointly shared by patients and their health care providers[1]. It aims at helping patients play an active role in decisions concerning their health[2], which is the ultimate goal of patient-centered care[3]. Shared decisionmaking rests on the best evidence of the risks and benefits of all the available options[4]. It includes the following components: establishing a context in which patients' views about treatment options are valued and deemed necessary, transferring technical information, making sure patients understand this information, helping patients base their preference on the best evidence; eliciting patients' preferences, sharing treatment recommendations, and making explicit the component of uncertainty in the clinical decision-making process[5]. A Cochrane systematic review of 34 randomized controlled trials of shared decision-making programs (also known as decision aids) indicates that compared to usual care or simple information leaflets, these programs: 1) improved knowledge, 2) produced more realistic expectations, 3 ) lowered decisional conflict, 4) increased the proportion of people active in decision-making, 5) reduced the proportion of people who remained undecided, and 6) produced greater agreement between values and choice[6].

Population-based and clinically-based surveys have shown that a significant proportion of respondents would like to play an active role in decisions concerning their health [7-9]. Although the nature of the problem may influence the amount of control patients want in making decisions for themselves[10,11], more and more individuals recognize that they are the best judges of their values when deliberating over a health care decision[12,13]. Indeed, as Deber (1996) pointed out, making decisions about one's own health consists of "problem-solving" and "decision making that requires the contribution of patients' values and preferences" [14]. While most patients do not wish to be involved in "problem-solving," most would like to be involved in the decision-making process[14]. In a recently published review on optimal matches of patient preferences for information, decision making, and interpersonal behaviour[15], findings from 14 studies showed that a substantial group of patients (26\% to $95 \%$ with a median of $52 \%$ ) was dissatisfied with the information given (in all aspects) and reported a desire for more information. In the same review, findings from six studies showed that the better the match between the information that was desired and the information that was received, the better the patient outcomes[15].

Nonetheless, shared decision-making has not yet been widely adopted by health care professionals[10,16-21]. If shared decision-making is desirable, more will need to be done to understand what factors hinder or facilitate its implementation in clinical practices[22]. Therefore, we sought to systematically review studies that reported on health professionals' perceived barriers and facilitators to implementing shared decision-making in their clinical practice.

\section{Methods \\ Search strategy}

Covering the period from 1990 to March 2006 and based on a list of 51 key articles in the field of shared decisionmaking (including a list of 17 studies that dealt with barriers and/or facilitators to implementing shared decisionmaking in clinical practice), specific search strategies were developed by an information specialist for the following databases: PubMed, Embase, CINHAL, et PsycINFO (see Additional file 1). The information specialist estimated that the proportion of retrieved articles that met our minimum definition of a key article in the field of shared decision-making (positive predictive value) was about $10 \%-$ $20 \%$, depending on the database. For Pubmed, the sensitivity of search strategy was $100 \%$ (proportion of preidentified key articles in the field of shared decision-making that were identified by his search strategy). In other words, all 51 articles provided to the information specialist were captured by his search strategy. Using the free text words "shared decision-making" or "participation of patient in decision" or "decision aids" or "decision support," Dissertation Abstracts also were searched. References from included studies and review articles[22,23] were scanned.

\section{Selection criteria}

A study was eligible for inclusion in the review if: 1) it was an original collection of data, 2) participants included health professionals, and 3) results included perceived barriers and/or facilitators to shared decision-making. Shared decision-making was defined in an inclusive manner as a joint process between health professionals and patients to make decisions $[5,24,25]$, or as decision support interventions such as decision aids[6], or as the active participation of patients in decision making. We did not restrict our search and inclusion of studies to those reporting as their main objective the assessment of barriers and facilitators to shared decision-making. Thus, we included studies that provided usable data for either of these two outcomes. No study design was excluded, and only studies in French and English were assessed. When more than one publication described a single study and each presented the same data, we included only the most recent publication. However, when more than one publication described a single study but each presented new and complementary data, we included them all. 


\section{Study identification and data extraction}

One individual (KG) screened all references. Two reviewers (FL and KG) extracted data independently using a data extraction sheet. At the time this review was conducted and to the best of our knowledge, there was no taxonomy for assessing barriers and facilitators to the implementation of shared decision-making in clinical practice. Therefore, a data extraction sheet was created by using a template analytic approach, "beginning with a basic set of codes based on a priori theoretical understanding and expanding on these codes by readings of the text" [26]. The beginning set of a priori codes was based on a taxonomy of barriers and facilitators to implementing clinical practice guidelines in actual practice $[27,28]$. This taxonomy had been used successfully to study factors affecting general practitioners' decisions about plain radiography for back pain by Espeland and colleagues (2003), who concluded that it compared well to other taxonomies[28]. Following previous work by one of the authors[29], we further enriched this taxonomy with some of the attributes of innovations (Table 1)[30].

Both reviewers independently read each publication and identified the unit of text (a sentence or paragraph representing one idea) relevant to each of the main outcomes of interest (barriers or facilitators to the implementation of shared decision-making in clinical practice). Each unit of text was then coded according to the relevant and preestablished code list and entered into an Excel spreadsheet. Units of text which could not be coded were discussed by the two assessors and new codes were created as necessary, thus refining and expanding the preliminary list of codes. Discrepancies between the coders were resolved through iterative discussions. During the coding process, codes (e.g., lack of agreement with the applicability of shared decision-making to practice population based on the age of the patient) were aggregated into themes (e.g., lack of agreement with the applicability of shared decision-making to practice population based on the characteristics of the patient), which in turn were nested under the main theme - lack of agreement with the applicability of shared decision-making. Themes were ordered according to the number of studies in which they were identified.

\section{Quality assessment}

Study characteristics were abstracted and included: country of origin, year and language of publication, main objective of the study, operationalization of shared decision-making, use of a conceptual framework to assess barriers and/or facilitators to the implementation of shared decision-making in practice, design of study within which barriers and facilitators were elicited, characteristics of participants, sampling strategy, response rate, and methodological approach, including data collection strategies.
Quality assessment of included studies was based on an existing framework and its set of validated tools[31,32]. This framework was selected because its authors provide reviewers with an extensive manual for quality scoring of quantitative, qualitative and mixed methods studies. The manual also includes definitions and detailed instructions[31]. Two reviewers (KG and FL) independently assessed the quality of each study. Discrepancies between the two coders were resolved through discussion. As the review did not involve human subjects, ethical approval for the study was not sought.

\section{Results \\ Included studies}

From PubMed, Embase, CINHAL, PsycINFO et Dissertation Abstracts, we screened 9580 references and assessed the full text of 170 documents. Thirty one publications $[11,21,29,33-60]$ relating to 28 unique studies met our inclusion criteria, among which were two unpublished doctoral dissertations $[33,42]$. Three publications presenting additional but distinct data were from the same randomized controlled trial[21,35,36], and two were from the same cross-sectional study $[54,55]$. Thus, we abstracted data from each one of them. The number of publications/studies included at the various stages of the review process is shown in Additional file 2 (see Additional file 2).

\section{Study characteristics}

The characteristics of included studies are shown in Additional file 3 (see Additional file 3). Studies were published in English, except for one that was published in French[53]. Most studies originated in the United Kingdom ( $\mathrm{n}=$ 11) $[21,35-39,43,45,47-49,56,58]$, followed by the United States $(\mathrm{n}=8)[11,33,40-42,44,51,54,55]$, Canada $(\mathrm{n}=$ $4)[29,34,46,52]$, Netherlands $(\mathrm{n}=2)[50,59]$, France $(\mathrm{n}=$ 1)[53], Mexico ( $\mathrm{n}=1)$ [57], and Australia $(\mathrm{n}=1)$ [60]. One study from the Netherlands had enrolled health professionals from 11 countries (Austria, Belgium, Denmark, France, Germany, Israel, The Netherlands, Portugal, Slovenia, Switzerland, UK)[50]. Therefore, included studies reported data from health professionals in 15 countries. More than half of the studies were published in or after $2004(\mathrm{n}=16)[34-36,43,49-60]$.

Only two studies were explicit in their use of a conceptual framework pertaining to the assessment of barriers and/or facilitators to the implementation of best practices in clinical practice[42,52]. Designs of study within which barriers and facilitators elicited included: cross sectional $(\mathrm{n}=$ 24)[11,29,33,34,37-46,48-51,53-55,58-60], randomized clinical trial $(\mathrm{n}=3)[21,35,36,47,52]$, and before-and-after $(\mathrm{n}=1)$ [57]. Ten studies were based on a probabilistic sampling frame[11,33,34,42,45,46,49-52]. Response rates were mentioned in 13 studies and varied from $42 \%$ 
Table I: Taxonomy of barriers and facilitators and their definitions

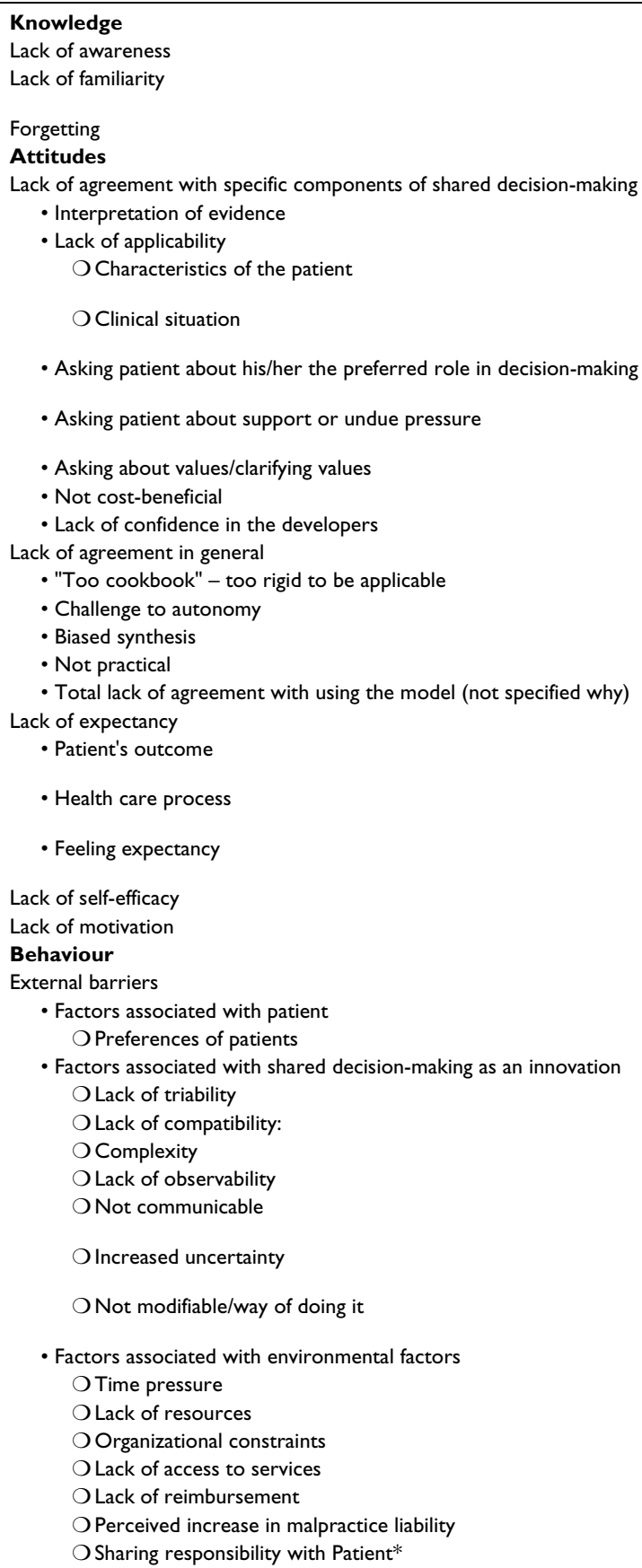

Inability to correctly acknowledge the existence of shared decision-making (SDM) [27] Inability to correctly answer questions about SDM content, as well as self-reported lack of familiarity [27]

Inadvertently omitting to implement SDM [4I]

Not believing that specific elements of SDM are supported by scientific evidence [27]

Lack of agreement with the applicability of SDM to practice population based on the characteristics of the patient [27]

Lack of agreement with the applicability of SDM to practice population based on the clinical situation [27]

Lack of agreement with a specific component of SDM such as asking patients about their preferred role in decision-making [27]

Lack of agreement with a specific component of SDM such as asking patients about support and/or undue pressure [27]

Lack of agreement with a specific component of SDM such as asking patients about values [27] Perception that there will be increased costs if SDM is implemented [28]

Lack of confidence in the individuals who are responsible for developing or presenting SDM [27]

Lack of agreement with SDM because it is too artificial [27]

Lack of agreement with SDM because it is a threat to professional autonomy [27]

Perception that the authors were biased [27]

Lack of agreement with SDM because it is unclear or impractical to follow [28]

Lack of agreement with SDM in general (unspecified) [27]

Perception that performance following the use of SDM will not lead to improved patient outcome [27]

Perception that performance following the use of SDM will not lead to improved health care process [28]

Perception that performance following the use of SDM will provoke difficult feelings and/or does not take into account existing feelings [28]

Belief that one cannot perform SDM [27]

Lack of motivation to use SDM or to change one's habits [27]

Perceived inability to reconcile patient preferences with the use of SDM [27]

Perception that SDM cannot be experimented with on a limited basis [30]

Perception that SDM is not consistent with one's own approach [30]

Perception that SDM is difficult to understand and to put into use [30]

Lack of visibility of the results of using SDM [30]

Perception that it is not possible to create and share information with one another in order to reach a mutual understanding of SDM [30]

Perception that the use of SDM will increase uncertainty (for example, lack of predictability, of structure, of information [30]

Lack of flexibility in the degree to which SDM is not changeable or modifiable by a user in the process of its adoption and implementation [30]

Insufficient time to put SDM into practice [30]

Insufficient materials or staff to put SDM into practice [28]

Insufficient support from the organization

Inadequate access to actual or alternative health care services to put SDM into practice [28]

Insufficient reimbursement for putting SDM into practice [28]

Risk of legal actions is increased if SDM is put into practice [28]

Using SDM lowers the responsibility of the health professional because it is shared with patient

* Only for the facilitator assessment taxonomy

to $97 \%[11,29,33,34,37,38,41,42,46,48,52,53,58]$. Two studies did not report the number of participants[44,47]. In those that did, this number varied from 6 to 914 . Overall, in studies that reported the number of participants, most of the participants were physicians (2481 out of a total of 2784 participants) $[11,21,29,33$ 43, 45, 46, 48-51, 53-60]. Most studies used qualitative methods exclusively $(\mathrm{n}=18)[29,37-39,41,43-45,47-51$, 54-56, 58-60]. Six used quantitative methods exclusively $[11,33,34,40,46,53]$, and four used mixed methods $[21,35,36,42,52,57]$. Data collection strategies included individual interviews $(\mathrm{n}=15)[21,29,35,36$, $39,42,43,45,47,49-52,57-60]$, self-administered questionnaires $(\mathrm{n}=10)[11,21,33-36,40,42,46,53,56]$, 
focus groups $(\mathrm{n}=10)[21,35-38,43,44,48,52,54,55$, 57, 60], and observation $(\mathrm{n}=3)[41,47,57]$.

\section{Quality assessment of included studies}

Table 2 shows the quality assessment of included studies. Except for two studies[44,56], most qualitative studies (n $=16 / 18$ ) had an average score of $50 \%$ or more[29,37$39,41,43,45,47-51,54,55,58-60]$. It is interesting to note that no qualitative study explicitly provided an account of reflexivity. In other words, researchers did not reflect on the influence that their backgrounds and interests might have had on their results. Overall, quantitative studies had an average score of $50 \%$ or more $[11,33,34,40,46,53]$. Mixed methods studies had an average score of $50 \%$ or more in both assessments (qualitative and quantitative) $[21,35,36,42,52,57]$.

\section{Barriers and facilitators}

Six publications focused solely on identifying barriers $[21,40,45,48,53,59]$, while two focused solely on identifying facilitators $[46,58]$. Most focused on both barriers and facilitators[11,29,33-39,41-44,47,49-52,54-57]. Table 3 summarizes the barriers and facilitators that were reported. In order of frequency, the five most often identified barriers were: time constraints (18/28)[29,34$39,41-43,47,48,50,51,53-57,60]$, lack of applicability due to patient characteristics $(12 / 28)[21,29,34,37,41,43,47$ $49,53-55,59]$, lack of applicability due to the clinical situation (12/28)[11,29,34,36-38,47-49,53-55,59], perceived patient preferences for a model of decision-making that did not fit a shared decision-making model $(\mathrm{n}=$ 9) $[21,39,41,42,45,47,48,52,54,55]$, and not agreeing with asking patients about their preferred role in decisionmaking $(\mathrm{n}=7)[11,38,40,42,43,50,59]$.

In order of frequency, the five most often identified facilitators were: motivation of health professionals $(\mathrm{n}=15)[33,35,36,38,39,41-4447,49,51,52,54$, $55,57,58]$, perception that shared decision-making will lead to a positive impact on the clinical process $(\mathrm{n}=11)[11,29,33,34,36,41,42,50,51,54,55,57]$, perception that shared decision-making will lead to a positive impact on patient outcomes $(\mathrm{n}=10)[33,34,37,42$, $46,50-52,54-56]$, perceptions that SDM is useful/practical $(n=6)[29,33,41,54-57]$, patient preferences for decision-making fitting a shared decision-making model $(\mathrm{n}=$ $4)[34,39,42,52]$, and characteristics of the patient $(n=$ $4)[29,35,51,54,55]$. Removing the two qualitative studies that had an average quality assessment score of less than $50 \%$ did not change these results.

Possible positive impacts on process included: believing that involving patients in decision-making promotes trust and honesty and, in turn, leads to better diagnosis and care[51]; helping patients address all their concerns[54]; improvement of doctor-patient relationship[50]; and providing health professionals with more background information about patients, which would enable them to judge patient needs and preferences better[50]. Possible positive impacts on outcomes included: patients' acceptance of advice and adherence to medication[50]; patients' satisfaction, either by reducing their worries or by increasing their understanding of disease and treatment options [50]; satisfaction with the decision made[46]; and better health outcomes[51].

\section{Discussion}

In 1999, Frosch and Kaplan observed that there were few surveys of large samples of physicians on how they perceived shared decision-making[22]. Therefore, results of our systematic review are important because, to the best of our knowledge, they reflect the first to attempt to pull together the views of more than 2784 health professionals from 15 countries (most of them physicians) on barriers and facilitators to the implementation of shared decisionmaking in their clinical practice. These results should improve our understanding on how to effectively translate shared decision-making into health professionals' clinical practice.

Except for "lack of awareness," that is, the inability of health professionals to state that shared decision-making exists, the whole range of barriers initially proposed by Cabana and colleagues (1999) was identified[27]. Time constraint was the most often cited barrier for implementing shared decision-making in clinical practice. This is interesting because this was a major concern for health professionals across many different cultural and organizational contexts[29,34-39,41-43,47,48,50,51,53-57,60]. However, recent evidence about the time required to engage in a shared decision-making process in practice is conflicting[61,62]. Therefore, it will be important that future studies on the implementation of shared decisionmaking in practice investigate whether engaging in shared decision-making actually takes more time or not.

Lack of agreement with some specific aspects of SDM was the second and third most often cited theme of barriers for implementing shared decision-making in practice. It included the perceived lack of applicability due to the characteristics of patients and the lack of applicability due to the clinical situation. Perceived patient preferences for a decision-making model that does not fit SDM and not agreeing with asking patients about their preferred role in decision making were the fourth and fifth most reported barriers. Taken together, these are important because they suggest that health professionals might be screening a priori, which patients they believe are eligible for shared decision-making. This is of some concern because physicians may misjudge patients' desire for active involvement in 


\begin{tabular}{|c|c|c|c|c|c|c|c|c|c|c|c|c|c|c|c|c|c|c|}
\hline Qualitative studies & \multicolumn{18}{|c|}{ Study identification } \\
\hline Criteria & {$[60]$} & [37] & [38] & [39] & [29] & {$[4 I]$} & [43] & {$[44]$} & {$[45]$} & {$[51]$} & {$[54,55]$} & {$[58]$} & [59] & {$[47]$} & [48] & [49] & [56] & [50] \\
\hline Question/objective sufficiently described? & 2 & 2 & 2 & 2 & 2 & 1 & 2 & 0 & 2 & 2 & 2 & 2 & 1 & 2 & 2 & 2 & 2 & 2 \\
\hline Study design evident and appropriate? & 2 & 2 & 2 & 2 & 2 & 2 & 2 & 0 & 2 & 2 & 2 & 1 & 1 & 1 & 1 & 2 & 1 & 2 \\
\hline Context for the study clear? & 2 & 2 & 2 & 2 & 2 & 2 & 2 & 1 & 2 & 1 & 2 & 2 & 2 & 2 & 2 & 2 & 2 & 2 \\
\hline Connection to a theoretical framework/wider body of knowledge? & 2 & 2 & 2 & 2 & 2 & 2 & 2 & 0 & 1 & 1 & 2 & 2 & 2 & 1 & 1 & 2 & 2 & 2 \\
\hline Sampling strategy described, relevant and justified? & 1 & 1 & 1 & 1 & 1 & 2 & 1 & 0 & 2 & 2 & 1 & 1 & 1 & 1 & 1 & 2 & I & 2 \\
\hline Data collection methods clearly described and systematic? & 2 & 2 & 2 & 2 & 2 & 2 & 2 & 0 & 2 & 2 & 2 & 2 & 2 & 2 & 2 & 2 & 1 & 2 \\
\hline Data analysis clearly described and systematic? & 2 & 2 & 2 & 2 & 2 & 2 & 2 & 0 & 2 & 2 & 2 & 2 & I & 2 & I & 2 & 0 & 2 \\
\hline Use of verification procedure(s) to establish credibility? & 0 & 2 & 2 & 0 & 1 & 0 & 1 & 0 & 1 & 0 & 0 & 0 & 0 & 0 & 0 & 0 & 0 & 0 \\
\hline Conclusions supported by the results? & 2 & 2 & 2 & 2 & 2 & 2 & 2 & 2 & 2 & 2 & 1 & 2 & 2 & 2 & 2 & 2 & 0 & 2 \\
\hline Reflexivity accounted for? & 0 & 0 & 0 & 0 & 0 & 0 & 0 & 0 & 0 & 0 & 0 & 0 & 0 & 0 & 0 & 0 & 0 & 0 \\
\hline Total score/possible maximum score & $15 / 20$ & $17 / 20$ & $17 / 20$ & $15 / 20$ & $16 / 20$ & $15 / 20$ & $16 / 20$ & $3 / 20$ & $16 / 20$ & $14 / 20$ & $14 / 20$ & $14 / 20$ & $12 / 20$ & $13 / 20$ & $12 / 20$ & $16 / 20$ & $9 / 20$ & $16 / 20$ \\
\hline \multicolumn{19}{|l|}{ Quantitative studies } \\
\hline & \multicolumn{18}{|c|}{ Study identification } \\
\hline Criteria & & [53] & & & [33] & & & [34] & & & {$[40]$} & & & {$[11]$} & & & [46] & \\
\hline Question/objective sufficiently described? & & 2 & & & 2 & & & 2 & & & 2 & & & 2 & & & 2 & \\
\hline Study design evident and appropriate? & & 2 & & & 2 & & & 2 & & & 2 & & & 2 & & & 2 & \\
\hline $\begin{array}{l}\text { Method of subject/comparison group selection or source of information/input } \\
\text { variables described and appropriate? }\end{array}$ & & 1 & & & 2 & & & 2 & & & 1 & & & 2 & & & 2 & \\
\hline $\begin{array}{l}\text { Subject (and comparison group, if applicable) characteristics sufficiently } \\
\text { described? }\end{array}$ & & 2 & & & 2 & & & 2 & & & 2 & & & 2 & & & 2 & \\
\hline If interventional and random allocation was possible, was it described? & & N/A & & & N/A & & & N/A & & & N/A & & & N/A & & & N/A & \\
\hline If interventional and blinding of investigators was possible, was it reported? & & N/A & & & N/A & & & $N / A$ & & & N/A & & & N/A & & & N/A & \\
\hline If interventional and blinding of subjects was possible, was it reported? & & N/A & & & N/A & & & $N / A$ & & & N/A & & & $N / A$ & & & $N / A$ & \\
\hline $\begin{array}{l}\text { Outcome and (if applicable) exposure measure(s) well-defined and robust for } \\
\text { measurement/misclassification bias? Means of assessment reported? }\end{array}$ & & 2 & & & 2 & & & 2 & & & 2 & & & 2 & & & 2 & \\
\hline Sample size appropriate? & & N/A & & & N/A & & & N/A & & & N/A & & & N/A & & & N/A & \\
\hline Analytic methods described/justified and appropriate? & & 2 & & & 2 & & & 2 & & & 2 & & & 2 & & & 2 & \\
\hline Some estimate of variance is reported for the main results? & & N/A & & & 2 & & & 0 & & & 2 & & & 2 & & & 1 & \\
\hline Controlled for confounding? & & N/A & & & N/A & & & N/A & & & N/A & & & N/A & & & N/A & \\
\hline Results reported in sufficient detail? & & 2 & & & 2 & & & 2 & & & 2 & & & 2 & & & 2 & \\
\hline Conclusions supported by the results? & & 2 & & & 2 & & & 2 & & & 2 & & & 2 & & & 2 & \\
\hline Total score/possible maximum score & & $15 / 16$ & & & $18 / 18$ & & & $16 / 18$ & & & $17 / 18$ & & & $18 / 18$ & & & $17 / 18$ & \\
\hline
\end{tabular}

\footnotetext{
Mixed methods studies
} 
Table 2: Quality assessment of included studies (Continued)

\begin{tabular}{|c|c|c|c|c|}
\hline & \multicolumn{4}{|c|}{ Study identification } \\
\hline & {$[21,35,36]$} & [42] & {$[57]$} & [52] \\
\hline \multicolumn{5}{|l|}{ Assessment of the qualitative component of the study } \\
\hline \multicolumn{5}{|l|}{ Criteria } \\
\hline Question/objective sufficiently described? & 2 & 2 & 2 & 2 \\
\hline Study design evident and appropriate? & 2 & 2 & 2 & 2 \\
\hline Context for the study clear? & 2 & 2 & 2 & 2 \\
\hline Connection to a theoretical framework/wider body of knowledge? & 2 & 2 & 2 & 2 \\
\hline Sampling strategy described, relevant and justified? & 1 & 1 & 1 & 1 \\
\hline Data collection methods clearly described and systematic? & 2 & 2 & 2 & 2 \\
\hline Data analysis clearly described and systematic? & 2 & 2 & 2 & 2 \\
\hline Use of verification procedure(s) to establish credibility? & 0 & 2 & 0 & 0 \\
\hline Conclusions supported by the results? & 2 & 2 & 2 & 2 \\
\hline Reflexivity of the account? & 0 & 2 & 0 & 0 \\
\hline \multicolumn{5}{|l|}{ Assessment of the quantitative component of the study } \\
\hline Question/objective sufficiently described? & 2 & 2 & 2 & 2 \\
\hline Study design evident and appropriate? & 2 & 2 & 2 & 2 \\
\hline $\begin{array}{l}\text { Method of subject/comparison group selection or source of information/input } \\
\text { variables described and appropriate? }\end{array}$ & I & 2 & 1 & 2 \\
\hline $\begin{array}{l}\text { Subject (and comparison group, if applicable) characteristics sufficiently } \\
\text { described? }\end{array}$ & 2 & 2 & 2 & 2 \\
\hline If interventional and random allocation was possible, was it described? & 2 & N/A & N/A & $\mathrm{N} / \mathrm{A}$ \\
\hline If interventional and blinding of investigators was possible, was it reported? & 2 & N/A & $N / A$ & N/A \\
\hline If interventional and blinding of subjects was possible, was it reported? & 2 & $N / A$ & N/A & $\mathrm{N} / \mathrm{A}$ \\
\hline $\begin{array}{l}\text { Outcome and (if applicable) exposure measure(s) well-defined and robust for } \\
\text { measurement/misclassification bias? Means of assessment reported? }\end{array}$ & 2 & 2 & 2 & 2 \\
\hline Sample size appropriate? & 2 & $N / A$ & 2 & $\mathrm{~N} / \mathrm{A}$ \\
\hline Analytic methods described/justified and appropriate? & 2 & 2 & 1 & $\mathrm{~N} / \mathrm{A}$ \\
\hline Some estimate of variance is reported for the main results? & 2 & 2 & 1 & $\mathrm{~N} / \mathrm{A}$ \\
\hline Controlled for confounding? & I & $N / A$ & 1 & $\mathrm{~N} / \mathrm{A}$ \\
\hline Results reported in sufficient detail? & 2 & 2 & 2 & 2 \\
\hline Conclusions supported by the results? & 2 & 2 & 2 & 2 \\
\hline Total score/possible maximum score & $41 / 48$ & $37 / 38$ & $33 / 42$ & $29 / 34$ \\
\hline $\begin{array}{l}\text { 2: Yes } \\
\text { 1: Partial } \\
0: \text { No } \\
\text { N/A: Not applicable }\end{array}$ & & & & \\
\hline
\end{tabular}


6 Table 3: Perceived barriers and facilitators to implementation of shared decision-making in clinical practice

\begin{tabular}{|c|c|c|}
\hline Factor as a barrier/facilitator & $\begin{array}{l}\text { Barriers (number of studies in which this factor was identified as a } \\
\text { barrier) [reference number] }\end{array}$ & $\begin{array}{l}\text { Facilitators (number of studies in which this factor was identified as a } \\
\text { facilitator) [reference number] }\end{array}$ \\
\hline \multicolumn{3}{|l|}{ Knowledge } \\
\hline Lack of awareness/awareness & 0 & 0 \\
\hline Lack of familiarity/familiarity & $5[29,37,39,44,49]$ & 0 \\
\hline Forgetting & $\mathrm{I}[4 \mathrm{I}]$ & Not applicable \\
\hline \multicolumn{3}{|l|}{ Attitude } \\
\hline \multicolumn{3}{|c|}{ Lack of agreement with specific components of shared decision-making/agreement with specific components of shared decision-making } \\
\hline - Interpretation of evidence & I [29] & \\
\hline \multicolumn{3}{|l|}{ - Lack of applicability/applicability } \\
\hline OCharacteristics of the patient & $12[21,29,34,37,41,43,47-49,53-55,59]$ & $4[29,35,51,54,55]$ \\
\hline OClinical situation & $12[11,29,34,36-38,47-49,53-55,59]$ & $3[37,46,51]$ \\
\hline - Asking patient about his/her preferred role in decision-making & $7[11,38,40,42,43,50,59]$ & $2[42,50]$ \\
\hline - Asking patient about support or undue pressure & 0 & I [34] \\
\hline - Asking about values/clarifying values & 0 & 0 \\
\hline - Not cost-beneficial/Cost-beneficial & $3[21,29,45]$ & I [42] \\
\hline - Lack of confidence in the developers/Confidence in the developers & 0 & I [29] \\
\hline \multicolumn{3}{|l|}{ Lack of agreement in general/Agreement in general } \\
\hline • "Too cookbook" - too rigid to be applicable & $2[29,48]$ & 0 \\
\hline - Challenge to autonomy & $\mathrm{I}[\mathrm{II}]$ & 0 \\
\hline - Biased synthesis & I [29] & 0 \\
\hline - Not practical/Practical & $2[29,54,55]$ & $6[29,33,41,54-57]$ \\
\hline - Total lack of agreement with using the model (not specified why) & $2[47,50]$ & 0 \\
\hline \multicolumn{3}{|l|}{ Lack of expectancy/expectancy } \\
\hline - Patient's outcome & I [33] & $10[33,34,37,42,46,50-52,54-56]$ \\
\hline - Process expectancy & I [56] & $11[11,29,33,34,36,41,42,50,51,54,55,57]$ \\
\hline - Feeling expectancy & 0 & I [34] \\
\hline Lack of self-efficacy/Self-efficacy & $6[21,34,37,48,50,53]$ & 0 \\
\hline Lack of motivation/Motivation & $4[21,37,51,52]$ & $15[33,35,36,38,39,41-44,47,49,51,52,54,55,57,58]$ \\
\hline \multicolumn{3}{|l|}{ Behaviour } \\
\hline \multicolumn{3}{|l|}{ External factors } \\
\hline \multicolumn{3}{|l|}{ - Factors associated with patient } \\
\hline OPreferences of patients & $9[21,39,41,42,45,47,48,52,54,55]$ & $4[34,39,42,52]$ \\
\hline \multicolumn{3}{|l|}{ - Factors associated with shared decision-making as an innovation } \\
\hline O Lack of triability/Triability & $2[29,49]$ & I [29] \\
\hline OLack of compatibility/Compatibility: & $2[29,33]$ & $2[29,33]$ \\
\hline OComplexity/Ease of use & $3[21,29,45]$ & $2[29,56]$ \\
\hline O Lack of observability/Observable & I [29] & I [29] \\
\hline ONot communicable/Communicable & $3[29,38,49]$ & 0 \\
\hline Olncrease uncertainty/Decrease or manage one's own uncertainty & I [45] & I [37] \\
\hline ONot modifiable/Modifiable & I [37] & I [29] \\
\hline \multicolumn{3}{|l|}{ - Factors associated with environmental factors } \\
\hline OTime pressure/Save time & $18[29,34-39,41-43,47,48,50,51,53-57,60]$ & $3[29,42,54,55]$ \\
\hline OLack of resources/Resources & $4[35,47,50,53]$ & I [50] \\
\hline Organizational constraints/Organizational support & 0 & 0 \\
\hline L Lack of access to services/Access to services & $2[4 I, 60]$ & 0 \\
\hline O Lack of reimbursement/Reimbursement & 0 & 0 \\
\hline $\begin{array}{l}\text { OPerceived increase in malpractice liability/Perceived decrease in } \\
\text { malpractice liability }\end{array}$ & $2[47,48]$ & 0 \\
\hline OSharing responsibility with Patient & Not applicable & $3[37,42,51]$ \\
\hline
\end{tabular}


decision making[63]. Therefore, in order to not increase inequity in health (patients who are not invited to be involved in decision making regarding their health, but who want to be), it will be important to address this barrier when implementing shared decision-making. We agree with Holmes-Rovner and her colleagues (2000) that interventions directed at patients and the system will be needed in order for shared decision-making to be implemented in actual practice[41].

The three most frequently reported facilitators clustered under attitude were: 1) motivation of health professionals to put shared decision-making into practice, 2) their perceptions of patient outcome expectancy (the perception that putting SDM into practice will lead to improved patient outcomes), and 3) process expectancy (the perception that putting SDM into practice will lead to improved health care processes). These results are congruent with the literature on the changing behaviour of health professionals $[64,65]$. Together, they suggest that anticipating positive outcomes before trying a shared decision-making approach may influence its implementation in practice. In other words, health professionals need to be able to perceive that the use of shared decision-making with their patients will have positive outcomes on the patients themselves or the processes of care. Although this might appear to be a logical approach when implementing shared decision-making in actual practice, how it will be achieved is still unclear.

Other interesting results from this systematic review are as follows. Lack of self-efficacy and lack of familiarity with SDM were mentioned as perceived barriers to the implementation of shared decision-making in six $[21,34,37,48,50,53]$ and five studies[29,37,39,44,49], respectively. This suggests that strategies to implement SDM in clinical practice will need to include training activities targeting health professionals. Elwyn and colleagues (2004) have shown that it was possible to train physicians in shared decision-making[66]. However, future implementation studies in this field will need to focus on improving knowledge of how competencies in SDM can be sustained over time.

Notwithstanding its interesting results, our systematic review has some limitations. First, although we searched systematically and thoroughly for articles on perceived barriers and/or facilitators of implementing shared decision-making in clinical practice by health professionals, this is not a well-indexed field of research. Therefore, it is possible that some eligible studies were not included in this review. However, our search strategy had an estimated predictive positive value for key articles in shared decision-making of $10 \%-20 \%$. Also, we were able to show that some of the barriers and facilitators were quite consistent across a large number of studies. Second, like other researchers [67-71], we believe that mixed methods systematic reviews (MMSR) constitute an emerging field of research that is still in need of tools to help reviewers synthesize results from qualitative, as well as from quantitative and mixed methods studies. In this review, as much as possible, we made our overall process explicit[72], including our quality assessment strategy. In a recently published MMSR on the impact of clinical information retrieval technology on physicians, Pluye and colleagues emphasized that "No one-size-fits-all tool exists to appraise the methodological quality of qualitative research"[67]. In our own review, we decided to use an existing set of tools $[31,32]$ and provided a justification for our choice. In subsequent "sensitivity analyses, " in which we ranked the studies from the lowest score to the highest score on the quality assessment score, we observed that in order to experience significant changes in the results, one would need to remove 11 and 8 studies with the lowest score for the assessment of barriers and facilitators, respectively. Third, we used an existing taxonomy to classify barriers and facilitators[27]. This taxonomy had been developed and used to abstract data from previous studies on barriers and facilitators to implementing clinical practice guidelines[27]. It also had been used in original data collection $[28,73,74]$. Other taxonomies have been proposed to perform original data collection in studies aimed at identifying implementation problems[75]. It is possible that the use of another taxonomy to content-analyse the data might have modified our results[28]. However, as mentioned by Espeland and colleagues (2003), the taxonomy that was used compares well with other such taxonomies[28]. Fourth, we did not contact the authors of the included studies to verify data interpretation[69]. However, the use of information from process evaluations and contact with authors does not appear to substantially change the results of systematic reviews of knowledge translation[76]. Lastly, quantification of themes was provided only "to gain an overview of the qualitative material," including the exploration of variation between studies[77].

\section{Conclusion}

Given that implementation of shared decision-making in clinical practice is a relatively recent phenomenon of interest[23], we believe that the results of our systematic review have implications for the development of theory and for research in this field. The vast majority of the included studies did not report the explicit use of a barriers and/or facilitators assessment tool. In this systematic review, the explicit use of such a tool helped standardize the presentation of the many factors that are likely to influence the uptake of shared decision-making into clinical practice and facilitate the comparison between similar studies[78]. In turn, this should contribute to the elaboration of a theoretical base for translating shared decision- 
making into practice. As the fields of implementation science[79] and shared decision-making[80] mature, we hope that our understanding of factors that might hinder or facilitate the implementation of SDM into clinical practice will improve.

These results also can be used to help target priorities for future implementation studies of shared decision-making. For example, future studies on barriers and facilitators to the implementation of SDM could target nurses and pharmacists, two disciplines that have not been well studied but that have had a significant impact on the development of shared decision-making [6,41,81-87]. Overwhelmingly, published studies originated from the UK and the USA, suggesting clear leadership of their health service researchers in this area and possibly, larger contextual variables that will need to be taken into account in future studies. At the same time, this could be another limitation of our findings, as we need studies in all types of health care systems to fully understand cross-cultural and health care system impacts on the implementation of shared decision-making.

In this review, the same factor was sometimes identified as both a barrier and a facilitator to implementing shared decision-making. This situation has been reported previously in a study that explored the gap between knowledge and behaviour of physicians[88]. This points to the importance of developing a comprehensive understanding of the perceived barriers and facilitators. Therefore, a more in-depth exploration of these factors should be pursued in future qualitative studies. Quantitative studies also could be used to analyze surveys of large probabilistic samples of health professionals in this area. Items could be derived from the results of our systematic review. Multivariate statistical analyses could then be used to identify the barriers and facilitators that make the largest contribution to the outcome of interest: intention of health professionals to implement shared decision-making in their practice. Finally, these results provide some insight into the type of interventions that could be tested with more robust study designs in order to foster shared decisionmaking.

\section{Competing interests}

All authors declare that they have no conflicting financial interests.

One of the authors of this review, IG, also is the author of one of the included studies.

\section{Authors' contributions}

FL conceived the study, supervised KG's student project, validated the methods, validated the article selection, assessed the quality of the included studies, second-coded all included articles, analysed the results, and wrote the paper. KG selected the articles, assessed the quality of the included studies, first-coded all included articles, analysed the results, and reviewed the paper. IG validated the methods, analysed the results, and participated actively throughout the writing of the paper. FL is its guarantor.

\section{Additional material}

Additional file 1
DOC/Search strategies by data source
Click here for file
[http://www.biomedcentral.com/content/supplementary/1748-
5908-1-16-S1.doc]
Additional file 2
DOC/Number of publications/studies included at the various stages of the
review process
Click here for file
[http://www.biomedcentral.com/content/supplementary/1748-
5908-1-16-S2.doc]
Additional file 3
DOC/Characteristic of included studies ( $n=28$ )
Click here for file
[http://www.biomedcentral.com/content/supplementary/1748-
5908-1-16-S3.doc]

\section{Acknowledgements}

We thank Mr. Hugh Glassco for reviewing this manuscript. Dr. Légaré is Tier 2 Canada Research Chair in Implementation of Shared Decision-Making in Primary Care. Dr lan Graham is Vice-President of Knowledge Translation at Canadian Institute of Health Research.

\section{References}

I. Briss P, Rimer B, Reilley B, Coates RC, Lee NC, Mullen P, Corso P, Hutchinson $A B$, Hiatt R, Kerner J, et al.: Promoting informed decisions about cancer screening in communities and healthcare systems. Am J Prev Med 2004, 26:67-80.

2. Wetzels R, Wensing M, Grol R: Involving older patients in general/family practice. Concept, tools and implementation. European Association for Quality in General Practice/Family Medicine; 2004.

3. Howie J, Heaney D, Maxwell M: Quality, core values and the general practice consultation: issues of definition, measurement and delivery. Fam Pract 2004, $21: 458-468$.

4. Towle A, Godolphin W: Framework for teaching and learning informed shared decision-making [see comments]. BMJ 1999, 319:766-7I.

5. Elwyn G, Edwards A, Kinnersley P: Shared decision-making in primary care: the neglected second half of the consultation. BrJ Gen Pract 1999, 49:477-82.

6. O'Connor AM, Stacey D, Entwistle V, Llewellyn-Thomas H, Rovner D, Holmes-Rovner M, Tait V, Tetroe J, Fiset V, Barry M, et al:: Decision aids for people facing health treatment or screening decisions (Cochrane Review). Volume 3. Oxford: Update Software ed. The Cochrane Library; 2004.

7. Martin S: "Shared responsibility" becoming the new medical buzz phrase. CMAJ 2002, 167:295.

8. Magee H, Davis LJ, Coulter A: Public views on healthcare performance indicators and patient choice. J R Soc Med 2003, 96:338-42. 
9. Chamot E, Charvet A, Perneger TV: Women's Preferences for Doctor's Involvement in Decisions about Mammography Screening. Med Decis Making 2004, 24:379-85.

10. McKinstry B: Do patients wish to be involved in decision making in the consultation? A cross sectional survey with video vignettes. $B M J$ 2000, 32 I:867-7I

II. McKeown RE, Reininger BM, Martin M, Hoppmann RA: Shared decision-making: views of first-year residents and clinic patients. Acad Med 2002, 77:438-45.

12. Deber RB: Physicians in health care management: 8. The patient-physician partnership: decision making, problem solving and the desire to participate. CMA] |994, I5 I:423-7.

13. Department of Health: The Expert Patient: A new approach to chronic disease management for the 2 Ist century. NHS; 200I:35.

14. Deber RB, Kraetschmer N, Irvine J: What role do patients wish to play in treatment decision making? Arch Intern Med 1996 I56:|4|4-20.

15. Kiesler DJ, Auerbach SM: Optimal matches of patient preferences for information, decision-making and interpersonal behavior: Evidence, models and interventions. Patient Educ Couns 2006, 61:319-41.

16. Godolphin W, Towle A, McKendry R: Challenges in family practice related to informed and shared decision-making: a survey of preceptors of medical students. CMAJ 200I, 165:434-435

17. Makoul G, Arntson P, Schofield T: Health promotion in primary care: physician-patient communication and decision making about prescription medications. Soc Sci Med 1995, 4I: I24I-54

18. O'Connor AM, Drake E, Wells G, Tugwell P, Laupacis A, Elmslie T: A Survey of the Decision-Making Needs of Canadians Faced with Complex Health Decisions. Health Expectations 2003, 6:1-13.

19. Guimond P, Bunn H, O'Connor AM, Jacobsen MJ, Tait VK, Drake ER, Graham ID, Stacey D, Elmslie T: Validation of a tool to assess health practitioners' decision support and communication skills. Patient Educ Couns 2003, 50:235-45.

20. Elwyn G, Edwards A, Wensing M, Hood K, Atwell C, Grol R: Shared decision-making: developing the OPTION scale for measuring patient involvement. Qual Saf Health Care 2003, I 2:93-99.

21. Davis RE, Dolan G, Thomas S, Atwell C, Mead D, Nehammer S, Moseley L, Edwards A, Elwyn G: Exploring doctor and patient views about risk communication and shared decision-making in the consultation. Health Expect 2003, 6:198-207.

22. Frosch DL, Kaplan RM: Shared decision-making in clinical medicine: past research and future directions. Am J Prev Med 1999, 17:285-94

23. Scheibler $\mathrm{F}$, Janssen $\mathrm{C}$, Pfaff $\mathrm{H}$ : [Shared decision-making: an overview of international research literature]. Soz Praventivmed 2003, 48: I I-23.

24. Charles C, Gafni A, Whelan T: Shared decision-making in the medical encounter: what does it mean? (or it takes at least two to tango). Soc Sci Med 1997, 44:68I-92.

25. Towle A, Godolphin W: Framework for teaching and learning informed shared decision-making. BMJ 1999, 3 19:766-7|.

26. Crabtree B, Miller W: A Template Approach to Text Analysis: Developing and Using Codebooks. In Doing Qualitative Research Edited by: Crabtree B, Miller W. CA: Sage Publications; 1992:93-109.

27. Cabana MD, Rand CS, Powe NR, Wu AW, Wilson MH, Abboud P$A C$, Rubin HR: Why don't physicians follow clinical practice guidelines? A framework for improvement. JAMA 1999, 282: $\mid 458-65$.

28. Espeland $A A$, Baerheim $A A$ : Factors affecting general practitioners' decisions about plain radiography for back pain: implications for classification of guideline barriers - a qualitative study. BMC Health Serv Res 2003, 3:8.

29. Graham ID, Logan J, O'Connor A, Weeks KE, Aaron S, Cranney A Dales R, Elmslie T, Hebert P, Jolly E, et al.: A qualitative study of physicians' perceptions of three decision aids. Patient Educ Couns 2003, 2055: I-5

30. Rogers EM: Diffusion of innovations. Fourth edition. New York: The Free Press; 1995.

31. Kmet L, Lee R, Cook L: Standard quality assessment criteria for evaluating primary research papers from a variety of fields. Alberta Heritage Foundation for Medical Research; 2004:22.
32. Lee RC, Kmet L, Cook LS, Lorenzetti D, Godlovitch G, Einsiedel E: Risk assessment for inherited susceptibility to cancer: a review of the psychosocial and ethical dimensions. Genet Test 2005, 9:66-79.

33. Araki SS: Shared decision-making in the treatment of endometriosis pain. Cambridge, Massachusetts: Harvard University; 2003.

34. Charles C, Gafni A, Whelan T: Self-reported use of shared decision-making among breast cancer specialists and perceived barriers and facilitators to implementing this approach. Health Expect 2004, 7:338-48.

35. Edwards A, Elwyn G: Involving patients in decision making and communicating risk: a longitudinal evaluation of doctors' attitudes and confidence during a randomized trial. J Eval Clin Pract 2004, 10:431-7.

36. Edwards A, Elwyn G, Wood F, Atwell C, Prior L, Houston H: Shared decision-making and risk communication in practice: a qualitative study of GPs' experiences. Br J Gen Pract 2005, 55:6-13.

37. Elwyn G, Edwards A, Gwyn R, Grol R: Towards a feasible model for shared decision-making: focus group study with general practice registrars. BMJ 1999, 319:753-6.

38. Elwyn G, Edwards A, Kinnersley P, Grol R: Shared decision-making and the concept of equipoise: the competences of involving patients in healthcare choices. Br J Gen Pract 2000, 50:892-9.

39. Ford $\mathrm{S}$, Schofield T, Hope $\mathrm{T}$ : What are the ingredients for a successful evidence-based patient choice consultation?: A qualitative study. Soc Sci Med 2003, 56:589-602.

40. Hammond K, Bandak A, Williams M: Nurse, physician, and consumer role responsibility perceived by health care providers. Holist Nurs Pract 1999, 13:28-37.

4I. Holmes-Rovner M, Valade D, Orlowski C, Draus C, Nabozny-Valerio $B$, Keiser S: Implementing shared decision-making in routine practice: barriers and opportunities. Health Expect 2000, 3:182-19|.

42. Howell JW: Physicians' opinions about patient involvement in ehalth and medical care decisions and telephone-based decision support. Denver: University of Colorado; 1999.

43. Jones IR, Berney L, Kelly M, Doyal L, Griffiths C, Feder G, Hillier S, Rowlands G, Curtis S: Is patient involvement possible when decisions involve scarce resources? A qualitative study of decision-making in primary care. Soc Sci Med 2004, 59:93-102.

44. Keefe CW, Thompson ME, Noel MM: Medical students, clinical preventive services, and shared decision-making. Acad Med 2002, 77: II60-I.

45. Lewis DK, Robinson J, Wilkinson E: Factors involved in deciding to start preventive treatment: qualitative study of clinicians' and lay people's attitudes. BMJ 2003, 327:84I.

46. O'Connor AM, Llewellyn-Thomas HA, Sawka C, Pinfold SP, To T, Harrison DE: Physicians' opinions about decision aids for patients considering systemic adjuvant therapy for axillarynode negative breast cancer. Patient Educ Couns 1997, 30: I 43-53.

47. Stapleton H, Kirkham M, Thomas G: Qualitative study of evidence based leaflets in maternity care. BMJ 2002, 324:639.

48. Stevenson FA: General practitioners' views on shared decision-making: a qualitative analysis. Patient Educ Couns 2003, 50:29I-3.

49. Thistlethwaite J, van der Vleuten C: Informed shared decisionmaking: views and competencies of pre-registration house officers in hospital and general practice. Education for Primary Care 2004, 15:83-92.

50. Wetzels R, Geest TA, Wensing M, Ferreira PL, Grol R, Baker R: GPs' views on involvement of older patients: an European qualitative study. Patient Educ Couns 2004, 53:183-8.

5I. McGuire A, McCullough L, Weller S, Whitney S: Missed expectations? Physicians' views of patients' participation in medical decision-making. Medical Care 2005, 43:466-70.

52. Stacey D, Graham I, O'Connor AM, Pomey M: Barriers and facilitators influencing call center nurses' decision support for callers facing values-sensitive decisions: a mixed methods study. Worldviews on Evidence-Based Nursing 2005, 2: 184-195.

53. Andre N, Gaudart J, Bernard JL, Chabrol B: [How pediatric residents involve children during medical decision-making?]. Arch Pediatr 2005, I 2:1068-74.

54. Naik AD, Schulman-Green D, McCorkle R, Bradley EH, Bogardus ST Jr: Will older persons and their clinicians use a shared deci- 
sion-making instrument? Journal of General Internal Medicine 2005, 20:640-643.

55. Schulman-Green DJ, Naik AD, Bradley EH, McCorkle R, Bogardus ST: Goal setting as a shared decision-making strategy among clinicians and their older patients. Patient Educ Couns 2006.

56. Thomson P, Dowding D, Swanson V, Bland R, Mair C, Morrison A Taylor A, Beechey C, Niven CA: A computerised guidance tree (decision aid) for hypertension, based on decision analysis: Development and preliminary evaluation. Eur J Cardiovasc Nurs 2005.

57. Kim YM, Kols A, Martin A, Silva D, Rinehart W, Prammawat S, Johnson S, Church K: Promoting informed choice: evaluating a decision-making tool for family planning clients and providers in Mexico. Int Fam Plan Perspect 2005, 31 : 162-71.

58. Seale $C$, Chaplin R, Lelliott $P$, Quirk A: Sharing decisions in consultations involving anti-psychotic medication: $A$ qualitative study of psychiatrists' experiences. Soc Sci Med 2005.

59. Suurmond J, Seeleman C: Shared decision-making in an intercultural context: Barriers in the interaction between physicians and immigrant patients. Patient Education and Counseling 2006, 60:253-259.

60. Bajramovic J, Emmerton L, Tett SE: Perceptions around concordance - focus groups and semi-structured interviews conducted with consumers, pharmacists and general practitioners. Health Expectations 2004, 7:221-234.

61. Stacey D, O'Connor A, Graham I, Pomey M: Randomized controlled trial of the effectiveness of an intervention to implement evidence-based patient decision support into a nursing call centre. Journal of Telemedicine and Telecare in press.

62. Whelan T, Sawka C, Levine M, Gafni A, Reyno L, Willan AR, Math JJM, Dent S, Abu-Zahra H, Chouinard E, et al.: Helping patients make informed choices: a randomized trial of a decision aid for adjuvant chemotherapy in node-negative breast cancer. Journal of the National Cancer Institute 2003, 95:58I-587.

63. Bruera E, Willey JS, Palmer JL, Rosales M: Treatment decisions for breast carcinoma: patient preferences and physician perceptions. Cancer 2002, 94:2076-80.

64. Walker AE, Grimshaw JM, Armstrong EM: Salient beliefs and intentions to prescribe antibiotics for patients with a sore throat. Br J Health Psychol 200I, 6:347-360.

65. Légaré F, Godin G, Ringa V, Dodin S, Turcot L, Norton J: Variation in the psychosocial determinants of the intention to prescribe hormone therapy: a survey of GPs and gynaecologists in France and Quebec. BMC Med Inform Decis Mak 2005, 5:3I.

66. Elwyn G, Edwards A, Hood K, Robling M, Atwell C, Russell I, Wensing M, Grol R, The Study Steering G: Achieving involvement: process outcomes from a cluster randomized trial of shared decision-making skill development and use of risk communication aids in general practice. Fam Pract 2004, $21: 337-46$.

67. Pluye P, Grad RM, Dunikowski LG, Stephenson R: Impact of clinical information-retrieval technology on physicians: a literature review of quantitative, qualitative and mixed methods studies. Int J Med Inform 2005, 74:745-68.

68. Hardeman W, Griffin S, Johnston M, Kinmonth AL, Wareham NJ: Interventions to prevent weight gain: a systematic review of psychological models and behaviour change methods. Int J Obes Relat Metab Disord 2000, 24: I 3 I-43.

69. Mills EJ, Seely D, Rachlis B, Griffith L, Wu P, Wilson K, Ellis P, Wright JR: Barriers to participation in clinical trials of cancer: a meta-analysis and systematic review of patient-reported factors. Lancet Oncol 2006, 7:14|-8.

70. Vermeire E, Hearnshaw H, Van Royen P, Denekens J: Patient adherence to treatment: three decades of research. A comprehensive review. J Clin Pharm Ther 200I, 26:33I-42.

7I. Littlewood S, Ypinazar V, Margolis SA, Scherpbier A, Spencer J, Dornan $T$ : Early practical experience and the social responsiveness of clinical education: systematic review. BMJ 2005, 331:387-91.

72. Mulrow CD: Rationale for systematic reviews. BMJ 1994, 309:597-9.

73. Cruz-Correa M, Gross CP, Canto MI, Cabana M, Sampliner RE, Waring JP, McNeil-Solis C, Powe NR: The impact of practice guidelines in the management of Barrett esophagus: a national prospective cohort study of physicians. Arch Intern Med 200I, 161:2588-95.
74. Cabana MD, Rand CS, Becher OJ, Rubin HR: Reasons for pediatrician nonadherence to asthma guidelines. Arch Pediatr Adolesc Med 200I, I55: 1057-62.

75. Wensing M, Grol R: Methods to identify implementation problems. In Improving patient care. The implementation of change in clinical practice Edited by: Grol R, Wensing M, Eccles M. Oxford: Elsevier Butterworth Heinemann; 2005:109-2I.

76. Farmer A, Grimshaw J, Mayhew A, McGowan J, Graham I, Driedger M, Shojania K: Systematic reviews of knowledge translation interventions: contributions of process evaluations and contact with authors. CCOHTA Final Performance Report. University of Ottawa; 2006:36.

77. Malterud K: Qualitative research: standards, challenges, and guidelines. Lancet 200I, 358:483-8.

78. Saillour-Glenisson F, Michel P: [Individual and collective facilitators and barriers to the use of clinical guidelines by physicians: a literature review. Revue Épidémiologique de Santé Publique 2003, 5 I:65-80.

79. Werner A: A Guide to Implementation Research. Washington, DC: The Urban Institute; 2004.

80. Elwyn G: Idealistic, impractical, impossible? Shared decisionmaking in the real world. Br J Gen Pract 2006, 56:403-4.

8I. O'Connor AM: Validation of a decisional conflict scale. Med Decis Making 1995, 15:25-30.

82. O'Connor AM, Tugwell P, Wells GA, Elmslie T, Jolly E, Hollingworth G, McPherson R, Bunn H, Graham I, Drake E: A decision aid for women considering hormone therapy after menopause: decision support framework and evaluation. Patient Educ Couns 1998, 33:267-79.

83. Rothert ML, Talarczyk GJ: Patient Compliance and the Decision-Making Process of Clinicians and Patients. 1987:55-7I.

84. Rothert M, Padonu G, Holmes-Rovner M, Kroll J, Talarczyk G, Rovner D, Schmitt N, Breer L: Menopausal women as decision makers in health care. Exp Gerontol 1994, 29:463-8.

85. Rothert ML, Holmes-Rovner M, Rovner D, Kroll J, Breer L, Talarczyk G, Schmitt N, Padonu G, Wills C: An Educational Intervention as Decision Support for Menopausal Women. Research in Nursing and Health 1997, 20:377-87.

86. Holmes-Rovner M, Kroll J, Schmitt N, Rovner D, Breer L, Rothert M, Faan R, Padonu G, Talarczyk G: Patient Satisfaction with Health Care Decisions: The Satisfaction with Decision Scale. Med Decis Making 1996, 16:58-64.

87. Lalonde L, O'Connor AM, Drake E, Duguay P, Lowensteyn I, Grover SA: Development and preliminary testing of a patient decision aid to assist pharmaceutical care in the prevention of cardiovascular disease. Pharmacotherapy 2004, 24:909-22.

88. Kennedy T, Regehr G, Rosenfield J, Roberts SW, Lingard L: Exploring the gap between knowledge and behavior: a qualitative study of clinician action following an educational intervention. Acad Med 2004, 79:386-93.

Publish with Bio Med Central and every scientist can read your work free of charge

"BioMed Central will be the most significant development for disseminating the results of biomedical research in our lifetime. "

Sir Paul Nurse, Cancer Research UK

Your research papers will be:

- available free of charge to the entire biomedical community

- peer reviewed and published immediately upon acceptance

- cited in PubMed and archived on PubMed Central

- yours - you keep the copyright
BioMedcentral 